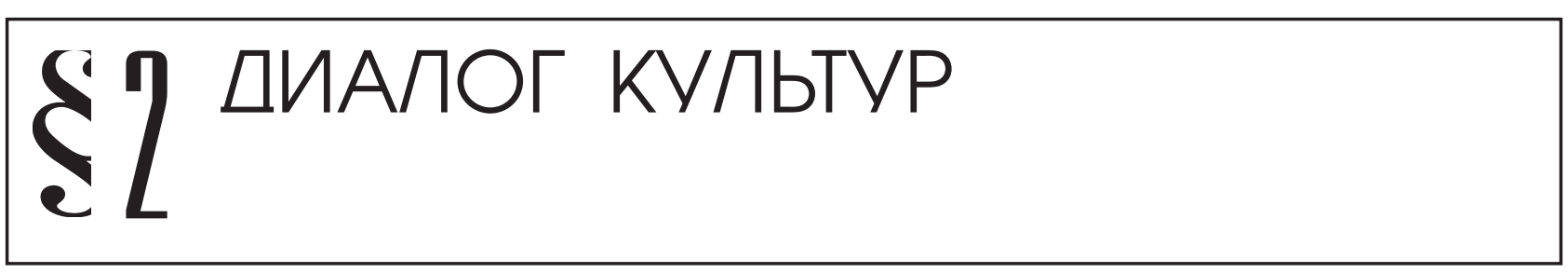

Попова A.B.

\title{
МОДЕЛЬ КРОССКУЛЬТУРНОЙ КОМПЕТЕНТНОСТИ ПЕДАГОГА ОБРАЗОВАТЕЛЬНОГО УЧРЕЖДЕНИЯ
}

Аннотация: В результате анализа психолого-педагогической литературы, изучающей особенности профессионального сознания педагога и специфику его деятельности в современных межкультурных условиях России, были выявлены основные противоречия между существующей практикой подготовки педагога и его конкретной профессиональной деятельностью. Эти противоречия особо проявляются в ситуациях межкультурного взаимодействия с субъектами педагогической деятельности, когда происходит столкновение национального и профессионального сознания. Для того чтобы препятствовать возникновению ошибок в ситуациях межкультурного взаимодействия, необходимо формировать как можно раньше у педагогов межкультурную (кросскультурную) компетенцию, которая является составляющей компетентности в общении с представителями других культур. В статье представлена модель кросскультурной компетентности педагога образовательного учреждения. В основу модели положена теория структурации Э. Гидденса о взаимообусловленности индивида и структуры. Компетентностный подход к формированию педагогического сознания в его кросскультурном компоненте, на наш взгляд, поможет педагогу не только адекватно действовать в имеющейся на сегодняиний день межкультурной среде, но и быть готовым к изменениям в ней, быть готовым к самостоятельной перестройке собственной педагогической деятельности, если того потребуют изменивииеся условия.

Review: By analyzing psychological and pedagogical literature on professional identity of teachers and special features of their teaching activities in the modern cross-cultural conditions of Russia, the author of the article defines the main contradictions between the current training of teachers and particular teaching activities. These contradictions show themselves in situations of cross-cultural interaction between actors of teaching activities when the national identity and professional identity encounter. In order to prevent errors in situations of cross-cultural interaction, it is necessary to create teachers' cross-cultural competence at the earliest state of their training. Such cross-cultural competence is the element of the general competence in communication with the representatives of other cultures. The author of the article presents the model of cross-cultural competence of a teacher at educational institution. The model is based on the structuration theory offered by Anthony Giddens. The author believes that the competence building approach to formation of the teacher's identity and cross-cultural competence will contribute to a teacher's success in today's cross-cultural environment, prepare him for any changes of the environment and allow him to change his teaching activity in accordance with changed conditions.

Ключевые слова: профессиональная деятельность, профессиональное сознание, компетентностный подход, кросскультурная компетентность, модель, способы реагирования, кросскультурная грамотность, этническая толерантность, кросскультурное взаимодействие, кросскультурная ситуация

Keywords: professional activities, professional identity, competency building approach, cross-cultural competence, model, reaction, cross-cultural skills, ethnic tolerance, cross-cultural interaction, cross-cultural situation.

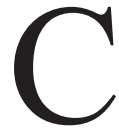

ерьезные изменения в политической, национальной и общественной сферах, а так же реализация приоритетного национального проекта «Образование», ставят новые целевые ориентиры в подготовке специалистов способных работать в современных кросскультурных условиях. Президент России Д.А. Медведев 27 декабря 2010 г. на совместном заседании Госсовета и Комиссии по реализации при- 


\section{Политика и общество 1 (109) • 2014}

оритетных национальных проектов и демографической политике объявил, о том, что без поддержания гражданского мира, межнационального и межконфессионального согласия в нашей стране не может быть никакого будущего ни у нас, ни у наших детей, невозможно сохранение и развитие самого государства. Стоит отметить, что вопросы межнациональных отношений ранее никогда не относились к приоритетам ни региональной, ни федеральной деятельности. В ноябре 2011 г. Д.А. Медведев на встрече с муфтиями в г. Уфа вновь вернулся к вопросу о межнациональном взаимодействии.

Россия исторически формировалась как многонациональная держава. К концу XX столетия существенным изменениям подверглась культурная и экономическая система даже тех общностей, которые в течение относительно долгого времени сохраняли приверженность традиционной культуре. Модернизация образа жизни привела к повышению неопределенности этнической идентичности и снижению ее позитивности ${ }^{1}$. В настоящее время в условиях разнообразия и многомерности социальных явлений поликультурность выступает важным условием устойчивого социального развития, обеспечивающим интеграцию каждого человека в мировое культурно-образовательное пространство ${ }^{2}$.

На современном этапе перед российской системой образования стоит задача осмысления и анализа происходящих в России кардинальных кросскультурных изменений: нередки случаи возникновения религиозной напряженности между представителями разных народов, факты национального унижения. Закон «Об образовании», Концепция модернизации образования и другие документы федерального уровня указывают на воспитание толерантности и формирование кросскультурной компетентности как на важные задачи образования, что предупреждает расизм, шовинизм, этноцентризм и т.д. ${ }^{3}$.

\footnotetext{
${ }^{1}$ Сыртланова, Н. Ш. Мультикультурная направленность регионального компонента дошкольного образования [текст] : диссертация ... кандидата педагогических наук : 13.00.07 / Н.Ш. Сыртланова. - Уфа, 2008. - 187 с.

${ }^{2}$ Белогуриов, А. Идея поликультурности в образовательном процессе [текст] // Высшее образование России / А. Белогурцов. - 2005. - №3. - С. 109.

${ }^{3}$ Конвенция о правах ребенка [Электронный ресурc]: http:// www.un.org/russian/ documen /convents/ childcon.htm/ (дата обращения: 18.04.2010).
}

Воспитатель детского сада или учитель школы - один из тех взрослых, кто вводит детей в мир человеческой культуры. Новые требования в поликультурной системе образования предполагают высокий профессионализм педагогов, который определяется составляющими его кросскультурной компетенции.

В результате анализа психолого-педагогической литературы, изучающей особенности профессионального сознания педагога ДОУ и специфику его деятельности в современных кросскультурных условиях России, были выявлены основные противоречия между существующей практикой подготовки педагога и его конкретной профессиональной деятельностью. Эти противоречия особо проявляются в ситуациях межкультурного взаимодействия с субъектами педагогической деятельности, когда происходит столкновение национального и профессионального сознания.

Национальное сознание формируется в длительном процессе усвоения личностью определенной системы знаний, норм, ценностей, позволяющих ей функционировать в качестве полноправного члена общества. В то время как профессиональное сознание включает систему знаний, норм и ценностей, обеспечивающие профессиональную деятельность педагога. В ходе педагогической деятельности в кросскультурных условиях происходит постоянное столкновение национального и профессионального сознаний. Зачастую, особенно в конфликтных ситуациях, на первый план выступает национальное сознание, вследствие чего педагог совершает ошибки в межкультурных ситуациях взаимодействия.

Современное образование требует усиление специальных знаний, умений, навыков в ситуациях межкультурного взаимодействия от педагогов. По мнению Н.Ш. Сыртлановой, воспитатели должны:

- знать народную культуру, историю, традиции, национальные особенности народов, представленных в социально-этнической среде дошкольной группы;

- уметь использовать знания в воспитательнообразовательном процессе, в сфере устно-народного, музыкально-игрового, декоративноприкладного фольклора; 
- владеть коммуникативными навыками, современными культурными моделями поведения ${ }^{4}$.

Основной составляющей педагогической деятельности является изучение национально-психологических ценностей различных этнических общностей. Педагогу необходимо предварительно познакомиться с обычаями и традициями народов, с представителями которых имеют дело, тогда он придет в многонациональный коллектив уже с определенными представлениями о формах поведения будущих подопечных, их возможных реакциях на те или иные воспитательные мероприятия, а также способах стимулирования их социально ориентированной деятельности. Воспитателю важно постоянно анализировать складывающиеся ситуации в межнациональных отношениях, проводить работу по изучению национально-психологических особенностей детей, способствуя созданию дружественных отношений в группе. Помимо этого, педагоги должны обладать высокой культурой межнационального общения, чувством такта, деликатностью в отношениях с представителями различных этносов. Чтобы оказать на них воспитательное воздействие, необходимо быть знакомым с их национально-психологическими ценностями ${ }^{5}$.

По мнению В.Ю. Хотинец, решающим периодом развития этнического самосознания является студенческий возраст. Дальнейшее его изменения представляют уже трансформацию в зависимости от экономических, демографических, социально-экономических условий жизнедеятельности этноса. В связи с этим необходимо формировать кросскультурную компетентность у студентов-педагогов в процессе обучения в вузе, чтобы избежать ошибок в ситуациях межкультурного взаимодействия.

С каждым годом в образовательных учреждениях увеличивается количество детей, для которых Россия не является родной страной. Перед большинством учреждений страны стоит задача интеграции детей других национальностей в жизнь группы, класса в целом. Эта проблема решается практически на всех возрастных этапах.

Среди педагогов, занимающихся с детьми из нерусских семей, существует несколько основных позиций по отношению к русскому языку и детямиммигрантам. «Их можно расположить по шкале терпимости - от полного неприятия и нежелания делать что-либо для поддержки детей и их родного языка до стремления ввести дополнительные занятия по их родному языку, от отношения к двуязычию как досадному отклонению от нормы до желания сделать всех российских детей, в т.ч. и говорящих только по-русски, по крайне мере, двуязычными (если другие говорят на нескольких языках, почему русские в этом ограничены?)» ${ }^{6}$.

Е.А. Панько выделяет в деятельности педагога ДОУ четыре группы умений. Гностические умения дают возможность познать предмет деятельности, а также оценить эффективность применяемых методов воспитания и обучения. Они тесно связаны со знанием психологии, пониманием закономерностей и особенностей развития детей, развитием психологической наблюдательности. Конструктивные умения помогают воспитателю проектировать различные виды деятельности, личность каждого ребенка или группы в целом. Организаторские умения помогают организовать как свою деятельность, так и деятельность детей. Коммуникативные умения помогают установить контакт с отдельными детьми или со всей группой, администрацией, коллегами, родителями. Все эти профессиональные умения взаимосвязаны ${ }^{7}$.

В кросскультурных ситуациях, на наш взгляд, коммуникативные умения приобретают особую значимость. В кросскультурную компетентность входит способность устанавливать и поддерживать необходимые контакты с другими людьми в ситуациях межкультурного взаимодействия. Адекватное взаимопонимание участников коммуникации, принадлежащих к разным национальным культурам, исследователи трактуют

\footnotetext{
${ }^{4}$ Сыртланова, Н. Ш. Мультикультурная направленность регионального компонента дошкольного образования [текст]: диссертация ... кандидата педагогических наук: 13.00.07 / Н.Ш. Сыртланова. -Уфа, 2008. -с. 71.

${ }^{5}$ Мудрик, A.B. Социализация вчера и сегодня [текст] / А.В. Мудрик. - М.: Московский психолого-социальный институт, 2001. - c. 34 .
}

${ }^{6}$ Протасова, Е.Ю. Многоязычие в детском саду [текст] / Е.Ю. Протасова, Н.М. Родина // Справочник старшего воспитателя дошкольного учреждения, 2008.- №1. - С. 4-13.

${ }^{7}$ Панько, Е.А. Психология деятельности воспитателя детского сада [текст] : Учеб. пособие для пед. Ин-тов / Е.А. Панько. - Минск: Издательство «Вышэйшая школа», 1986. 


\section{Политика и общество 1 (109) • 2014}

как межкультурную коммуникацию ${ }^{8}$. Отсутствие коммуникатив-ных умений у педагога приводит к возникновению конфликтов в ситуа-циях межкультурного взаимодействия.

Таким образом, для того чтобы препятствовать возникновению ошибок в ситуациях межкультурного взаимодействия, необходимо формировать как можно раньше у педагогов межкультурную (кросскультурную) компетенцию, которая является составляющей компетентности в общении с представителями других культур (А.С. Купавская и др.). Исследователи выделяют межкультурную, этнокультурную, этнопедагогическую, этнопсихологическую, поликультурную компетентности, которые являются синонимами понятию «кросскультурная компетентность».

Манойлова М.А. и др. сходятся во мнении что, развитие кросскультурной компетентности педагога будет способствовать повышению степени его психической адаптации к внутренней и кросскультурной (внешней) среде. Нарушение этнической идентичности может привести к появлению напряженности как в межличностном взаимодействии, так и в межгрупповом, что в дальнейшем будет проявляться в возникновении национальной розни и межэтнических конфликтах ${ }^{9}$.

Таким образом, обобщая различные подходы к определению «кросскультурная компетентность», основными ее структурными компонентами являются: способы реагирования в ситуациях межкультурного взаимодействия; кросскультурная грамотность; типы этнической идентичности; ценностная сфера, вербальные и невербальные коммуникации, религия, обычаи и традиции и т.д.

В ходе исследования была разработана модель кросскультурной компетентности педагога дошкольного образовательного учреждения, которая представлена на рис. 1.

\footnotetext{
${ }^{8}$ Верещзагин, Е.М., Костомаров, В.Г. Язык и культура: лингвострановедение в препода-вании русского языка как иностранного [текст] / Е.М. Верещагин, В.Г. Костомаров. - М.: Русский язык, 1976. - 276 с.

${ }^{9}$ Манойлова, M.A. Культурно-когнитивный компонент полиэтнической компетентности специалистов образования [текст] / М.А. Манойлова // Ученые записки МГПУ. Психологические науки: Сборник научных статей/ Науч. ред. И.А. Синкевич, А.А. Сергеева. - Мурманск: МГПУ, 2010. - Вып. 10.
}

В основу модели положена теория структурации Э. Гидденса о взаимообусловленности индивида и структуры. Согласно теории, ребенок, только родившись, включается в этническое пространство: его окружают предметы, которые могут представлять определенную ценность для того или иного этноса, вокруг него люди говорят на определенном языке, который является родным для определенной этнической группы. То есть, человек существует в пространстве наполненном культурной основой, являющейся ценностью для этнической группы. Когда человек растет, его мир расширяется, следовательно, расширяется и ценностное пространство, в процесс его социализации включаются огромное количество институтов претендующих на роль институтов социализации, в том числе и этнической (такие как школа, окружение человека, религиозные институты, самый важный институт формирования этнической идентичности - семья, и много других).

Таким образом, именно институты предлагают ценностно-нормативную базу для формирования этнической идентичности.

Однако факт существования этнических маргиналов доказывает тот факт, что человек принимает непосредственное участие в формировании своей идентичности, поскольку структура ценностей и ценностные ориентации, предлагаемые институтами социализации, не усваивается всеми в таком виде, в котором она предлагается ими. Процесс социализации - процесс двусторонний. Человек может принять ценности, а может и не принять. На данном этапе включаются механизмы персонификации ценностей, либо их отторжение. Далее человек может стать этническим маргиналом ${ }^{10}$.

Таким образом, факторами формирования этнической идентичности являются этническое пространство (семья, школа и т.д.), культурная основа (религии, обычаи, ценности) и включенность индивида в этнос (мотивационно-целевой компонент).

${ }^{10}$ Giddens, A. The constitution of society [текст] / A.Giddens. Oxford: Polity Press, 1997. - 179 p. 


\section{Факторы формирования этнической идентичности}

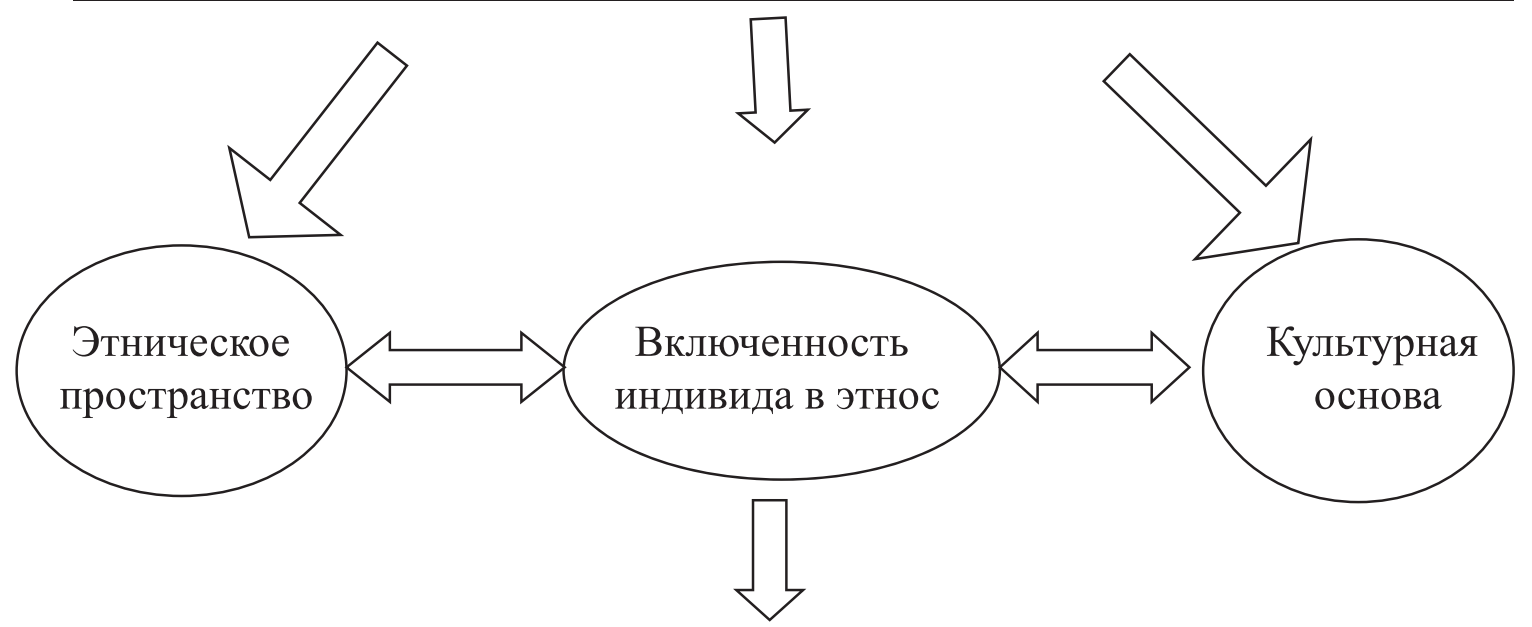

\section{Типы этнической идентичности}

\begin{tabular}{|c|c|c|c|c|c|}
\hline Этнонигилизм & $\begin{array}{c}\text { Этническая } \\
\text { индифферент- } \\
\text { ность }\end{array}$ & Норма & Этноэгоизм & $\begin{array}{c}\text { Этноизоляцио- } \\
\text { низм }\end{array}$ & Этнофанатизм \\
\hline
\end{tabular}
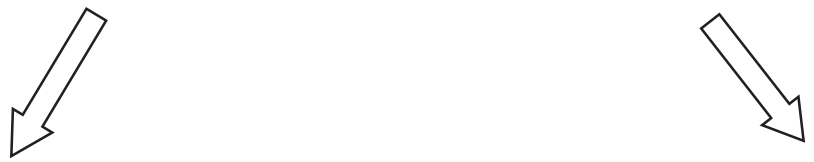

\begin{tabular}{|c|c|c|c|c|}
\hline \multicolumn{3}{|c|}{ Кросскультурная грамотность } & \multicolumn{2}{c|}{ Этническая } \\
толерантность
\end{tabular}

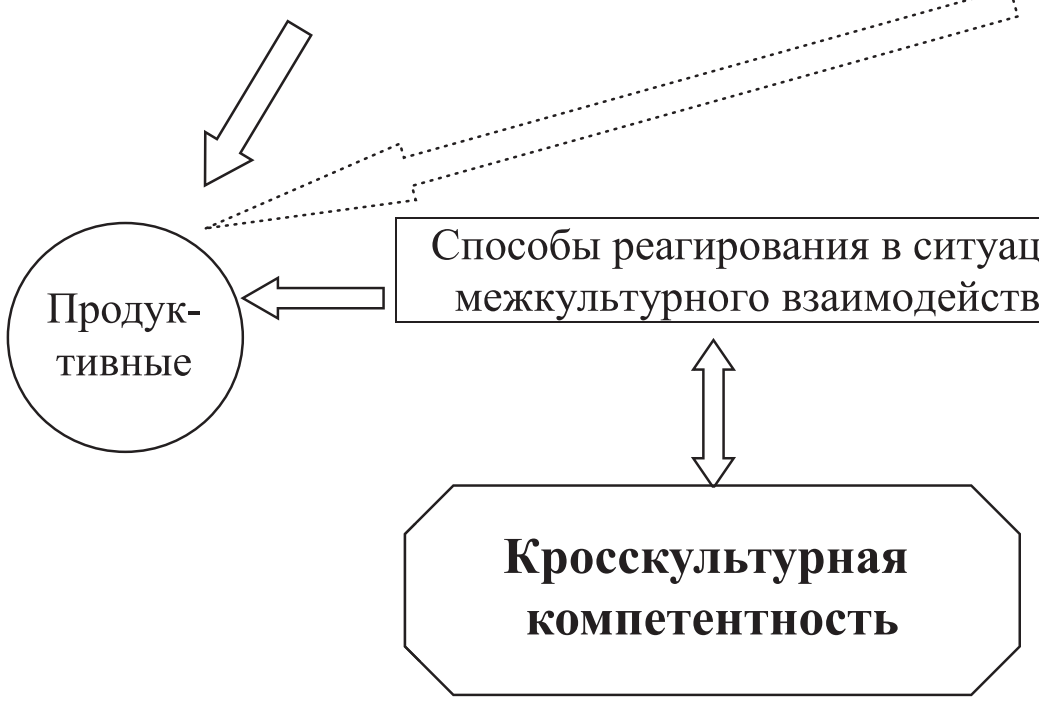

(C) NOTA BENE (OOO «НБ-Медиа») www.nbpublish.com

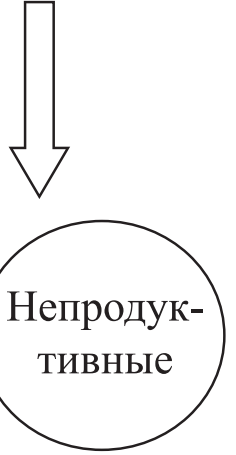

Puc. 1. 1.

Кросскультурная компетентность педагога ДОУ 


\section{Политика и общество 1 (109) • 2014}

Залогом взаимопонимания разных народов на межкультурном уровне является кросскультурная грамотность, под которой понимается умение человека принимать содержание и формы культуры другого народа, участвовать в совместной культурной деятельности, обогащающей и развивающей его как личность (В.Г. Рощупкин). Кросскультурная грамотность, по нашему мнению, является одним из условий кросскультурной компетентности, обеспечивающая эффективные межкультурные контакты в процессе педагогической деятельности. Знание, различение и использование продуктивных способов субъект-субъектного взаимодействия в профессиональной деятельности педагогов ДОУ будет способствовать развитию межличностных отношений. Толерантность-интолерантность педагога ДОУ - один из компонентов имплицитной составляющей профессионального сознания, который оказывает влияние на межличностные отношения в процессе профессиональной деятельности и взаимодействия в кросскультурных ситуациях.

Как отмечает О.Н. Недосека, формирование кросскультурной компетентности возможно при условии организации специальной работы в процессе профессиональной подготовки, направленной на развитие индивидуального сознания и ценностных ориентаций будущих педагогов. Ценностные ориентации выполняют мотивационную роль, являясь регулятором профессионального поведения, а источником их развития являются нравственные ценности общества, усваиваемые в процессе воспитания и обучения на всех этапах личностного и профессионального становления (В.Ф. Сержантов, В.Д. Шадриков, Е.А. Климов).

Кросскультурная компетентность педагога - совокупность способностей, типов поведения и практической деятельности, которые позволяют индивидам эффективно и осмысленно взаимодействовать с другими индивидами, социокультурная среда которых отличается от их собственной. Вместе с тем, кросскультурная компетентность - это не только характеристика определенной совокупности сложившихся способностей, но и процесс. Мы рассматриваем кросскультурную компетентность как процесс обучения способам реагирования в ситуациях межкультурного взаимодействия, направленных на взаимопонимание и развитие филантропических установок сознания ${ }^{11}$.

Следует отметить, что и компетентностный подход и система «кросскультурного образования», а так же ряд других походов, направленных на формирование кросскультурной компетентности педагога, не учитывают в полной мере того обстоятельства, что глубинные и устойчивые изменения в деятельности невозможны без соответствующего уровня развития, сформированности соответствующих структур профессионального сознания педагога и специально организованной работы.

Профессиональное сознание не складывается из набора или даже системы разнообразных компетентностей. Компетентность - это не только знание, но и умение строить, перестраивать и совершенствовать собственную деятельность, то есть компетентность - это проявление сознания в его рефлексивном, смысловом отношении. Компетентностный подход к формированию педагогического сознания в его кросскультурном компоненте, на наш взгляд, поможет педагогу не только адекватно действовать в имеющейся на сегодняшний день межкультурной среде, но и быть готовым к изменениям в ней, быть готовым к самостоятельной перестройке собственной педагогической деятельности, если того потребуют изменившиеся условия.

\section{Библиография:}

1. Белогурцов, А. Идея поликультурности в образовательном процессе [текст] // Высшее образование России / А. Белогурцов. - 2005. - №3. C. 109-112.

2. Верещагин, Е. М., Костомаров, В.Г. Язык и культура: лингвострановедение в преподавании русского языка как иностранного [текст] / Е.M. Верещагин, В.Г. Костомаров. -М. : Русский язык, 1976. $-276 \mathrm{c}$.

\footnotetext{
11 Науменко, А.В. Исследование кросскультурной компетентности педагогов-психологов дошкольных образовательных учреждений [текст] / О.Н. Недосека, А.В. Науменко // Вектор науки Тольяттинского государственного университета. Серия: Педагогика, психология. - № 3(6), 2011. - C. 219-223 - ISSN 2221-5662
} 
3. Конвенция о правах ребенка [Электронный ресурc]: http://www.un.org/russian/ documen convents/ childcon.htm/ (дата обращения : 18.04.2010).

4. Концепция дошкольного воспитания [текст] // Дошкольное воспитание. - 1989. - №5. - с. 10-23.

5. Манойлова, М. А. Культурно-когнитивный компонент полиэтнической компетентности специалистов образования [текст] / М.А. Манойлова // Ученые записки МГПУ. Психологические науки : Сборник научных статей/ Науч. ред. И.А. Синкевич, А. А. Сергеева. - Мурманск: МГПУ, 2010. - Вып. 10.

6. Мудрик, А.В. Социализация вчера и сегодня [текст] / А.В. Мудрик. - М. : Московский психолого-социальный институт, 2001. - 432 с.

7. Науменко, А. В. Исследование кросскультурной компетентности педагогов-психологов дошкольных образовательных учреждений [текст] / О.Н. Недосека, А.В. Науменко // Вектор науки Тольяттинского государственного университета. Серия : Педагогика, психология.-№ 3(6), 2011. - С. 219223 - ISSN 2221-5662.

8. Панько, Е. А. Психология деятельности воспитателя детского сада [текст] : Учеб. пособие для пед. Ин-тов / Е.А. Панько. - Минск : Вышэйшая школа, 1986.

9. Протасова, Е. Ю. Многоязычие в детском саду [текст] / Е.Ю. Протасова, Н.М. Родина // Справочник старшего воспитателя дошкольного учреждения, 2008.-№1. - С. 4-13.

10. Сыртланова, Н. Ш. Мультикультурная направленность регионального компонента дошкольного образования [текст] : диссертация ... кандидата педагогических наук : 13.00.07 / Н.Ш. Сыртланова.-Уфа, 2008.-187 с.

11. Giddens, A. The constitution of society [текст] / A.Giddens. - Oxford : Polity Press, 1997. - 179 p.

12. Науменко, А.В. Особенности кросскультурной компетентности педагога (дошкольное образовательное учреждение как структурный компонент профессионального сознания)[текст] // Психология и психотехника.-2011.-3.-С. 97-104.

13. Тарасова, С.М. Сформированность профессиональной компетентности как фактор успешной социальной адаптации [текст] // Психология и психотехника.- 2011. - 4. - С. 96 - 101.

\section{References (transliteration):}

1. Belogurtsov,A. Ideya polikul'turnostiv obrazovatel'nom protsesse [tekst] // Vysshee obrazovanie Rossii / A. Belogurtsov. - 2005. - №3. - S. 109-112.

2. Vereshchagin, E. M., Kostomarov, V.G. Yazyk i kul'tura: lingvostranovedenie v prepodavanii russkogo yazyka kak inostrannogo [tekst] / E.M. Vereshchagin, V.G. Kostomarov. -M. : Russkii yazyk, 1976. - 276 s.

3. Manoilova, M. A. Kul'turno-kognitivnyi komponent polietnicheskoi kompetentnosti spetsialistov obrazovaniya [tekst] / M.A. Manoilova // Uchenye zapiski MGPU. Psikhologicheskie nauki : Sbornik nauchnykh statei/ Nauch. red. I.A. Sinkevich, A. A. Sergeeva. - Murmansk: MGPU, 2010. - Vyp. 10.

4. Mudrik, A.V. Sotsializatsiya vchera i segodnya [tekst] / A.V. Mudrik. - M. : Mo-skovskii psikhologo-sotsial'nyi institut, 2001. - $432 \mathrm{~s}$.

5. Naumenko, A. V. Issledovanie krosskul'turnoi kompetentnosti pedagogov-psikhologov doshkol'nykh obrazovatel'nykh uchrezhdenii [tekst] / O.N. Nedoseka, A.V. Naumenko//Vektor nauki Tol'yattinskogo gosudarstvennogo universiteta. Seriya : Pedagogika, psikhologiya. - № 3(6), 2011. - S. 219-223 - ISSN 2221-5662 .

6. Pan'ko, E. A. Psikhologiya deyatel'nosti vospitatelya detskogo sada [tekst] : Ucheb. posobie dlya ped. In-tov / E.A. Pan'ko. - Minsk : Vysheishaya shkola, 1986.

7. Protasova, E. Yu. Mnogoyazychie v detskom sadu [tekst] / E.Yu. Protasova, N.M. Rodina // Spravochnik starshego vospitatelya doshkol'nogo uchrezhdeniya, 2008.-№1. - S. 4-13.

8. Syrtlanova, N. Sh. Mul'tikul'turnaya napravlennost' regional'nogo kompo-nenta doshkol'nogo obrazovaniya [tekst] : dissertatsiya ... kandidata pedagogiche-skikh nauk : 13.00.07 / N.Sh. Syrtlanova.-Ufa, 2008.-187 c.

9. Giddens, A. The constitution of society [tekst] / A.Giddens. - Oxford : Polity Press, 1997. - 179 p.

10. Naumenko, A.V. Osobennosti krosskul'turnoi kompetentnosti pedagoga (doshkol'noe obrazovatel'noe uchrezhdenie kak strukturnyi komponent professional'nogo soznaniya)[tekst] // Psikhologiya i psikhotekhnika.-2011.-3.-C. 97-104.

11. Tarasova, S.M. Sformirovannost' professional'noi kompetentnosti kak faktor uspeshnoi sotsial'noi adaptatsii [tekst] // Psikhologiya i psikhotekhnika. 2011. - 4. - C. 96-101. 